\title{
Effect of Skew Angle of Holes on the Thermal Fatigue Behavior of a Ni-based Single Crystal Superalloy
}

\author{
Zhong-Jiao Zhou ${ }^{1,2} \cdot$ Da-Qian $\mathrm{Yu}^{3} \cdot$ Li Wang ${ }^{1} \cdot$ Lang-Hong Lou ${ }^{1}$
}

Received: 11 January 2016/Revised: 15 August 2016/Published online: 8 December 2016

(C) The Chinese Society for Metals and Springer-Verlag Berlin Heidelberg 2016

\begin{abstract}
In the present work, holes of various skew angles were electrochemically machined in the middle of the plate specimens in a Ni-based single crystal superalloy and crack initiation and propagation around holes during thermal fatigue cycles $\left(20-1100{ }^{\circ} \mathrm{C}\right)$ were investigated. It was demonstrated that the skew angles had a significant effect on the initiation and propagation of thermal fatigue cracks. During thermal fatigue process, stress concentration occurred at the edge of the holes. As for skew angles, the maximum stress concentration appeared at the acute side of holes. The maximum stress concentration resulted in plastic deformation at the acute side of the $30^{\circ}$ hole, driving the thermal fatigue cracks to initiate after 220 cycles and propagate along [011] direction. However, the stresses concentrated at the edge of $90^{\circ}$ or $60^{\circ}$ holes were not large enough to initiate cracks even after 580 thermal cycles. This work will help to understand the local deformation behavior in the vicinity of cooling holes with various skew angles and have serious design implications for turbine blades.
\end{abstract}

\section{KEY WORDS: Ni-based single crystal superalloy; Thermal fatigue properties; Holes; Skew angles; Cracks}

\section{Introduction}

In modern gas turbines and aircraft engines, with increasing jet engine efficiency, the higher turbine inlet temperature (TIT) of advanced engines combined with the temperature-limited strength of candidate turbine materials has led to increasing dependence upon cooling systems to

Available online at http://link.springer.com/journal/40195

Li Wang

wangli@imr.ac.cn

1 Superalloys Division, Institute of Metal Research, Chinese Academy of Sciences, Shenyang 110016, China

2 Division of Micro/Nano Manufacturing, State Key Laboratory of Tribology, Tsinghua University, Beijing 100084, China

3 Material Design and Research Section, Beijing Huatsing Gas Turbine \& IGCC Technology Co., Ltd., Tsinghua Science Park, Beijing 100084, China meet design objectives [1]. To improve cooling efficiency, the turbine blades made of single crystal (SX) superalloys exhibit thin wall structure (the thinnest part of the blade is typically of the order of $0.5 \mathrm{~mm}$ ) and an intricate network of cooling holes on the surfaces most of which are inclined to the surface normal [2]. In service, turbine blades are subjected to repeated high stresses and temperatures in aggressive environments. In particular, they are exposed to sudden or steep variations in temperature (from ambient temperature to temperature of the order of $1100-1400{ }^{\circ} \mathrm{C}$ ) during engine start-up and shutdown [3, 4]. Thermal fatigue (TF) cracks often initiate and propagate at the edge of holes, which leads to the failure of blades [5, 6]. Therefore, understanding the crack initiation and propagation around the cooling holes during thermal cycles provides important information for the optimization of airfoil design and manufacture process.

The TF behavior of Ni-based superalloys has been widely studied [7-14]. It has been known that the thermal shock between the maximum and minimum values results 
in stresses and strains, and the mechanism of TF failure is essentially the accumulation of plastic deformation and rupture $[7,8]$. TF cracks are usually observed to initiate at slip bands, inclusions, carbides, grain boundaries, and micropores. The propagation of TF cracks is influenced by many factors, including: (1) the microstructure of samples which was reported that TF cracks propagated along the grain boundaries in polycrystalline samples [9], while the cracks propagated along $<110>$ orientations in columnar crystal [10] and SX samples [11-13]; (2) the properties of tested alloys, such as strength, ductility, thermal expansion coefficient, and thermal conductivity [3, 12-14], among which both material strength and ductility have been observed to improve TF life, but strength did not usually compensate for low ductility [3, 14]; (3) the testing conditions, including the maximum and minimum temperature, hold time at the maximum temperature, heating and cooling rates, and sample sizes [8].

The specimens used in the previous work are mainly wedge or disk specimen to simulate the thermal shock at the leading edge of blades, or plate specimens with notch to investigate the notch effect in turbine blades. However, these two kinds of specimens cannot evaluate the fatigue cracks initiated and propagated at the edge of cooling holes. Jin [15] compared the TF behaviors of specimens with a notch and a hole and found many TF cracks around the holes. The crack morphology and lifetime of specimens with a hole were more like the actual damages around cooling holes in turbine blades. Sheet samples with different secondary orientations or different hole sizes were prepared by Wang et al. [12, 13], and it was observed that both the secondary orientation and hole size had a great effect on the TF behaviors of SX superalloys. Moreover, to improve the cooling efficiency, most of cooling holes emerge at angles rather than normal to the surface. How skew angles affect the TF crack initiation and propagation around holes in Ni-based SX superalloys has not been reported.

In the present work, crack initiation and propagation around holes with various skew angles were investigated during TF cycles between 20 and $1100{ }^{\circ} \mathrm{C}$.

\section{Experimental}

SX bars of a third-generation Ni-based SX superalloy DD33 with $4 \%$ Re were used in the present study. To minimize the effect of misorientation on the deformation process, the initial orientations of all the SX bars used in the present experiment were within $3^{\circ}$ from [001] direction. All the bars were fully heat treated and the microstructure was composed of a matrix containing about $65 \%$ of well-aligned coherent cuboidal $\gamma^{\prime}$ precipitates, as shown in Fig. 1.
Plate specimens parallel to directional solidification (DS) direction and along (100) planes were cut from the SX bars with dimensions of $20 \mathrm{~mm} \times 10 \mathrm{~mm} \times 2 \mathrm{~mm}$ (Fig. 2). All the surfaces of the specimens were grinded and mechanically polished using standard metallographic technique. In each sample, a hole of $\phi 0.5 \mathrm{~mm}$ with different skew angles (skew angle $\alpha=90^{\circ}, 60^{\circ}$ and $30^{\circ}$ ) was machined in the center of the specimen. Figure 2 a shows the polar coordinates $x$ and $\beta$ of the hole. The skew angle $\alpha$ is defined as one between axes of the holes and the surface of the specimen. An ellipse was then produced on the sample surface as well as an acute side and an obtuse side on the cross section of the specimen, as illustrated in Fig. 2b, c. To avoid local material damage induced by the hole drilling process, all the holes were electrochemically machined (ECM). The morphologies of holes are shown in Fig. 3.

The specimens for $\mathrm{TF}$ test were heated to $1100{ }^{\circ} \mathrm{C}$ holding for $5 \mathrm{~min}$ in an electric resistance furnace followed by cooling to $20^{\circ} \mathrm{C}$ and holding for $1 \mathrm{~min}$. The temperature measurement error was limited to $\pm 3{ }^{\circ} \mathrm{C}$. The thermal cycle test was interrupted periodically to measure the crack length by optical microscopy (OM, Axio Vert.A1). The data were taken from the average crack length of three samples (two surfaces of each sample were observed), and the crack length was plotted as a function of the number of cycles. TF cracks and microstructure of the SX superalloy were investigated by $\mathrm{OM}$ and scanning electron microscopy (SEM, Hitachi S-3400 N) with energy-dispersive X-ray (EDX).

\section{Results}

\subsection{Crack Growth Kinetics of Specimens with Holes of Different Skew Angles}

The TF crack length as a function of the number of cycles is plotted in Fig. 4. As for specimens with a hole of $\alpha=30^{\circ}$, the crack initiation process required an incubation period and small cracks were generated after 220 cycles. And then, the crack length increased dramatically with increasing thermal cycles. However, much better TF resistance was observed for specimens with a hole of $\alpha=60^{\circ}$ or $90^{\circ}$. No TF cracks were observed even after 580 cycles.

\subsection{Initiation and propagation of TF cracks}

During TF tests after 20 cycles, oxidation occurred around the hole, as shown in Fig. 5. A total of five layers on the sample surface were identified. Starting from the edge of 

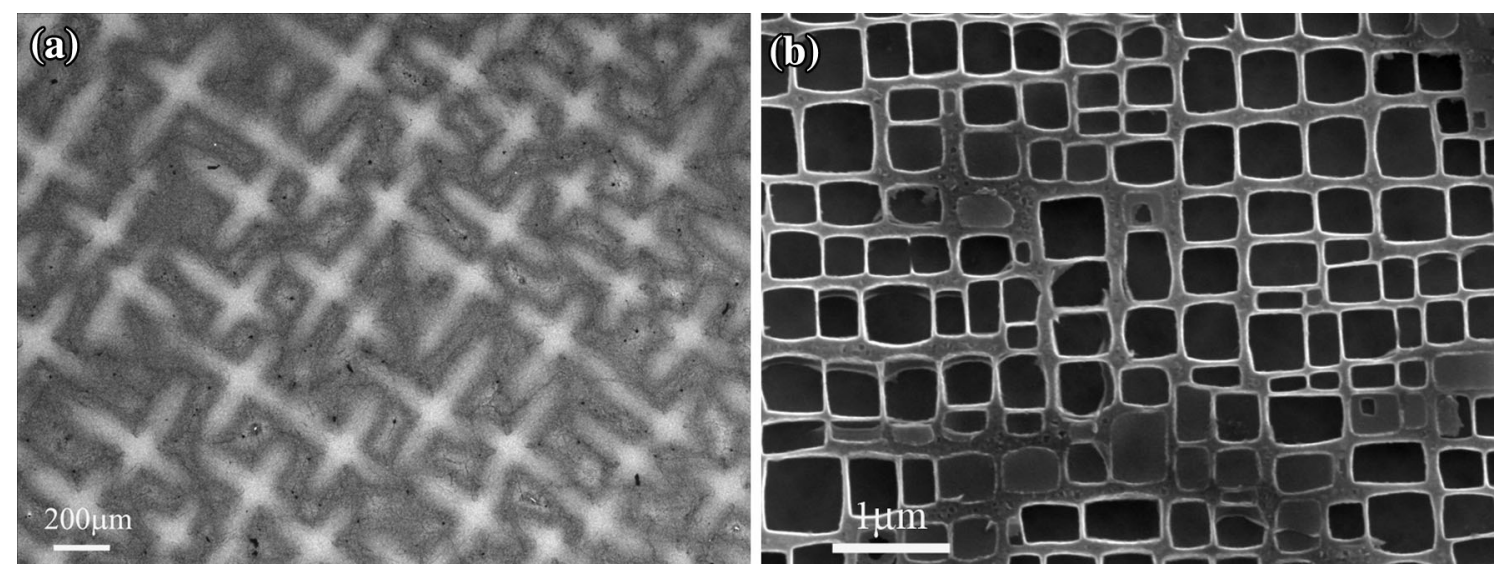

Fig. 1 a Dendritic structure of the experimental alloy, b two-phase $\gamma / \gamma^{\prime}$ microstructure of specimens after heat treatment

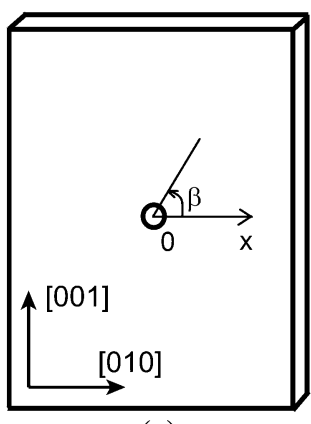

(a)

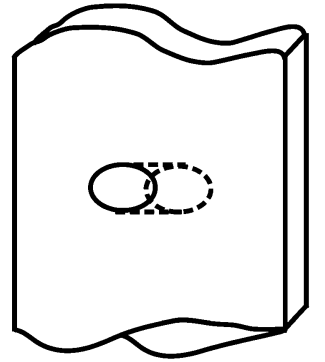

(b)

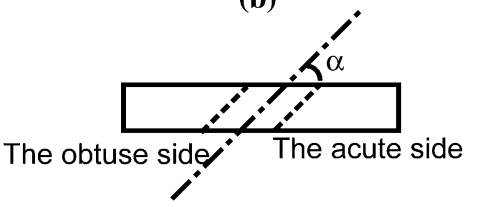

(c)
Fig. 2 Schematic of Ni-based SX superalloy samples for TF tests a, schematic illustration of skew holes $\mathbf{b}$, the obtuse and acute sides on the cross section $\mathbf{c}$

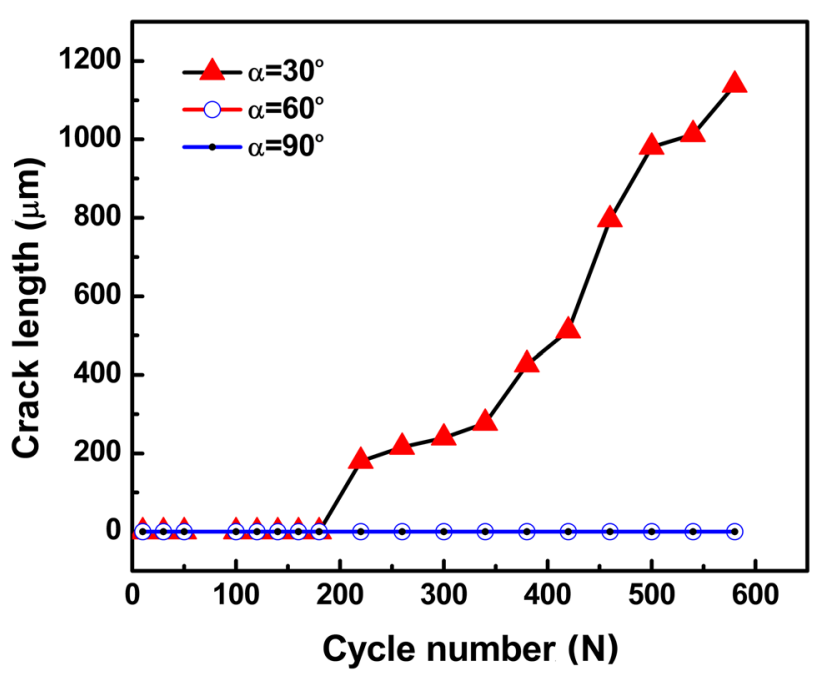

Fig. 4 Crack growth kinetics of samples with different skew angles
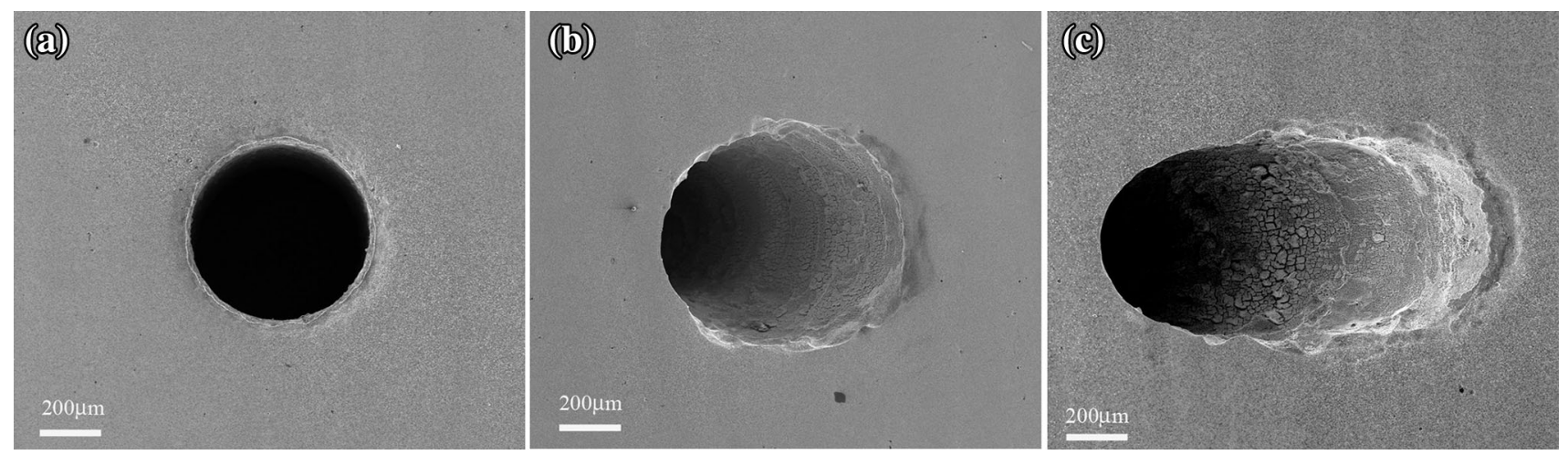

Fig. 3 Morphologies of holes of different skew angles: $\mathbf{a} \alpha=90^{\circ}, \mathbf{b} \alpha=60^{\circ}, \mathbf{c} \alpha=30^{\circ}$

hole, the oxide layer consisted of $\mathrm{NiO}$ layer, spinel layer, $\mathrm{Al}_{2} \mathrm{O}_{3}$ layer, mixed layer, and $\gamma^{\prime}$-denuded zone. The existence of the outermost layer of $\mathrm{NiO}$ was common to the Nibased superalloys. The compositions of the second layer were determined to contain main elements of $\mathrm{Ni}, \mathrm{Al}$, and $\mathrm{O}$ with trace elements of $\mathrm{Cr}$ and $\mathrm{Co}$, which should be the $\mathrm{Al}$, $\mathrm{Ni}, \mathrm{Co})(\mathrm{Al}, \mathrm{Cr})_{2} \mathrm{O}_{4}$ spinels layer. The third layer was $\alpha$ $\mathrm{Al}_{2} \mathrm{O}_{3}$ layer. According to the EDX results, the fourth layer 


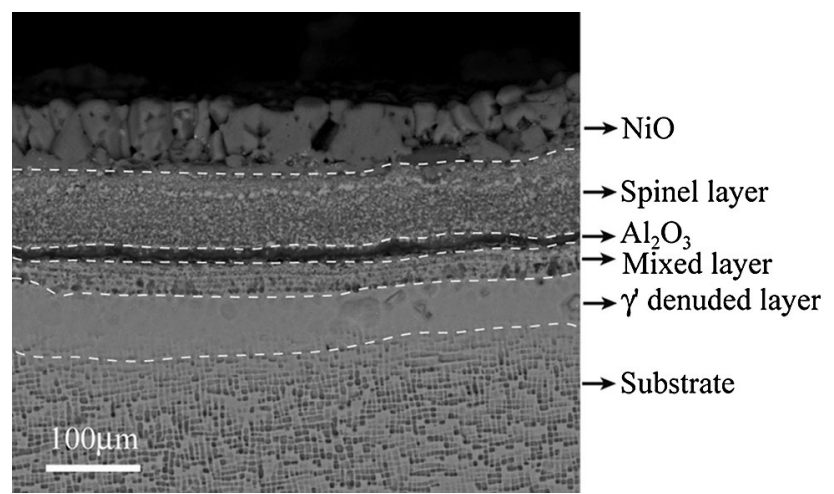

Fig. 5 Microstructure around the hole (20 cycles)

(mixed layer) was rich in $\mathrm{Ni}, \mathrm{Al}, \mathrm{O}, \mathrm{Cr}, \mathrm{Ta}$, and $\mathrm{W}$, which was formed by outward diffusion of $\mathrm{Al}$ and residuals $\mathrm{Ta}$ and $\mathrm{W}$ in the substrate. The innermost layer was $\gamma^{\prime}$-denuded zone with less $\mathrm{Al}, \mathrm{Ti}$, and $\mathrm{Cr}$.

Figure 6 shows the crack initiation and propagation for specimen with a hole of $\alpha=30^{\circ}$. SEM result reveals that microcracks were initiated at the acute side of the hole after 120 cycles, but no cracks were observed at the obtuse side (Fig. 6a, b). With further test to 180 cycles, no cracks were observed and the curvature radius of the acute side decreased while it kept constant at the obtuse side (Fig. 6c). The magnified view of the acute side showed the closure of the previous microcracks, as shown in Fig. 6d. With the increase in thermal cycles, a continuous decrease in curvature radius of the acute side was observed (Fig. 6e) and a thermal crack was initiated at the acute side of the hole and propagated along the $[0 \overline{1} 1]$ orientation (Fig. $6 f$ ). The zoomed views of the crack tip in marked regions in Fig. $6 \mathrm{f}$ are presented in Fig. $6 \mathrm{~g}$, h. The coarsened $\gamma^{\prime}$ precipitates near the crack tip were elongated circumferentially and arranged concentrically, forming the so-called concentrically oriented $\gamma^{\prime}$ rafting structure (as marked by the arrow in Fig. $6 \mathrm{~g}, \mathrm{~h}$ ), just as found in the previous works of K465 [16] and GTD-111 [17].

The TF behaviors of specimens with the hole of $60^{\circ}$ are shown in Fig. 7. A thick layer of oxidation was observed around the hole after 100 thermal cycles (Fig. 7a). Zoomed view of the edge of the hole (rectangular area in (a)) showed that slip traces along [011] direction were formed and extensive $\gamma^{\prime}$ rafts along [010] direction occurred (Fig. 7b). With increasing thermal cycles, the oxidation around the hole became thicker (Fig. 7c) and circumferential cracks (area A) were observed in the oxidation layer; the cracks propagated only within the oxidation layer and could not propagate into the substrate. As for $60^{\circ}$ holes, even after 540 thermal cycles, no TF cracks were initiated around the hole, just as shown in Fig. 7d.

Similar TF behaviors were observed for specimens with the hole of $90^{\circ}$, as shown in Fig. 8. Obvious oxidation
(Fig. 8a) and intensive slip traces along [011] direction (Fig. 8b) were presented at the edge of the hole after 140 cycles. With further increase in thermal cycles, the thicker oxidation layer and rafting of $\gamma^{\prime}$ were observed (Fig. 8c, d). But no cracks were initiated around the hole even after 540 thermal cycles (Fig. 8d).

\section{Discussion}

During TF cycles, the transient temperature gradients impose transient thermal strains and stresses on the inner edge of the hole. During heating stage, the inner edge of the hole is subjected to a compressive thermal stress due to the faster heating rate than that of the substrate. The compressive stress is maintained up to the highest temperature during TF cycles. During cooling, the thermal stress turns to be tensile at the inner edge of the hole due to the faster cooling rate. Therefore, the TF cycles can be approximately termed as a low cycle fatigue with compressiontension loading.

According to the linear elasticity theory, the edge of the hole perpendicular to the load axis experiences the maximum three-dimensional tensile stress, which results in early stress concentration [18]. Because Ni-based single crystal superalloy is fcc structure, under the high stress concentration at the edge of hole, the primary slip system, namely octahedral slip systems, will be activated and result in a large number of slip bands along $<110>$ direction.

As for an infinite plate with an elliptical hole, under the uniaxial tension perpendicular to the major axis of the ellipse, the maximum stress concentration factor $K_{\max }=$ $1+2 a / b \geq 3$ ( $a$ and $b$ are the major axis and minor axis of the ellipse, respectively) occurs, which is larger than that of the normal hole $\left(K_{\max }=3\right)$ [18]. For the skew hole, less deformation constraint from the surrounding material is available at the acute side [19], thus the strain is distributed asymmetrically and concentrated at the acute side of the hole, which was also observed in our previously tensile tests at room temperature [20]. In the present work, during cooling of the thermal cycles, the hole experiences tensile stress. The maximum stress is concentrated at the acute corners of the $30^{\circ}$ cooling holes [20]. With increasing thermal cycles, stress increases and causes the local material to deform plastically. As the overall strain is cycled back to zero during heating stage, the sample restores back to its starting state elastically except the acute corners which, due to their prior plastic deformation, are now still under a tensile stress [21]. The stress intensity factor, $K$, is calculated by using the following formula: $K=a_{1} \Delta \sigma \sqrt{\pi \sqrt{A}}$, where $\Delta \sigma$ refers to the stress amplitude, $A$ refers to area of defects projected on a plane normal to the loading axis, and $a_{1}$ can be regarded as constants for a 

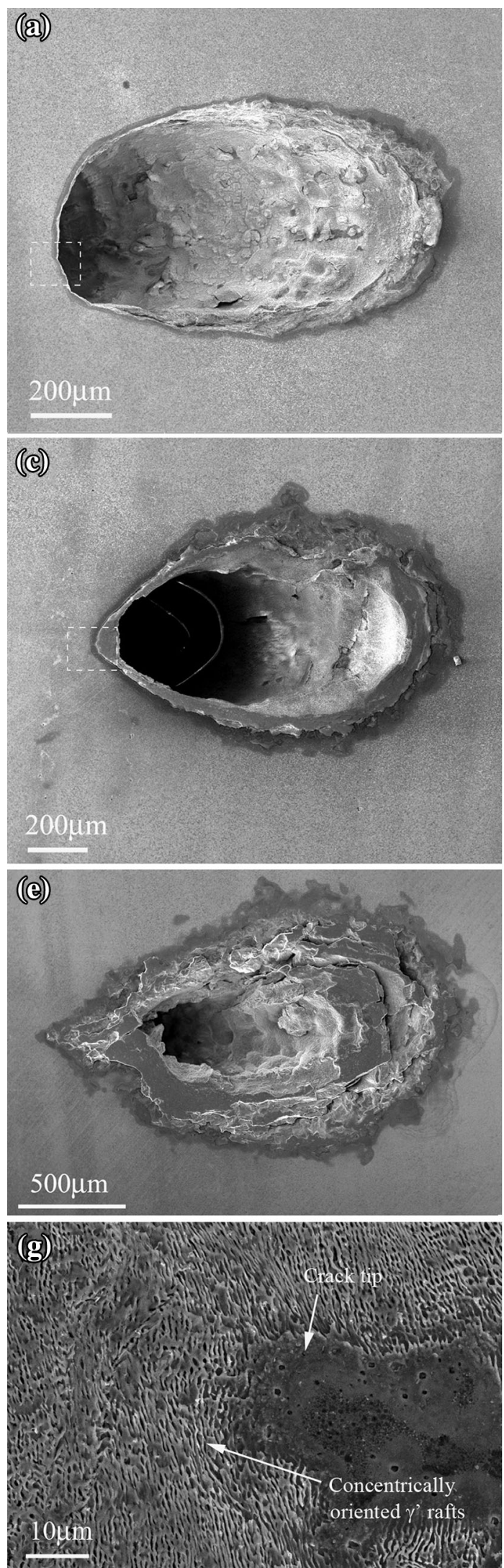

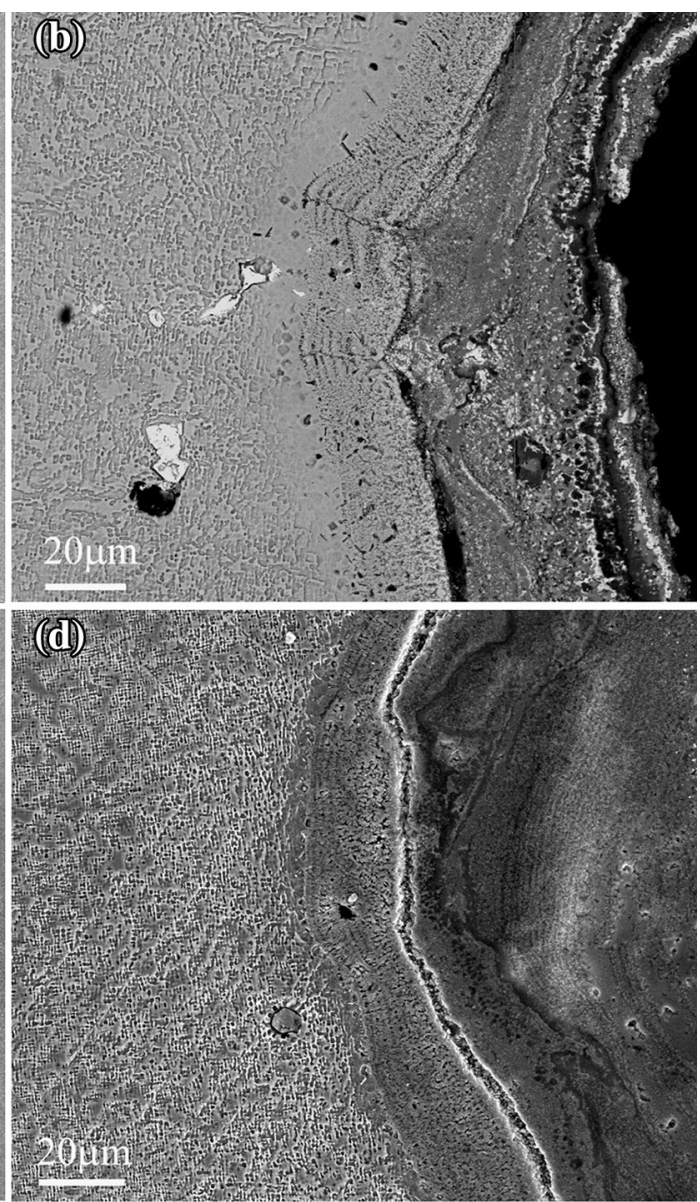

(I)

$500 \mu \mathrm{m}$

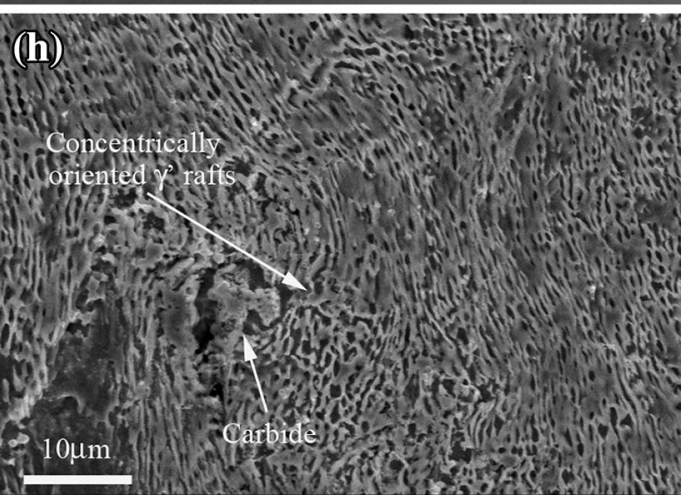

Fig. 6 Initiation and propagation of cracks around $30^{\circ}$ holes: a, b 120 cycles, c, d 180 cycles, e 260 cycles, f 540 cycles, g, h zoomed view of marked area in $\mathbf{f}$ 

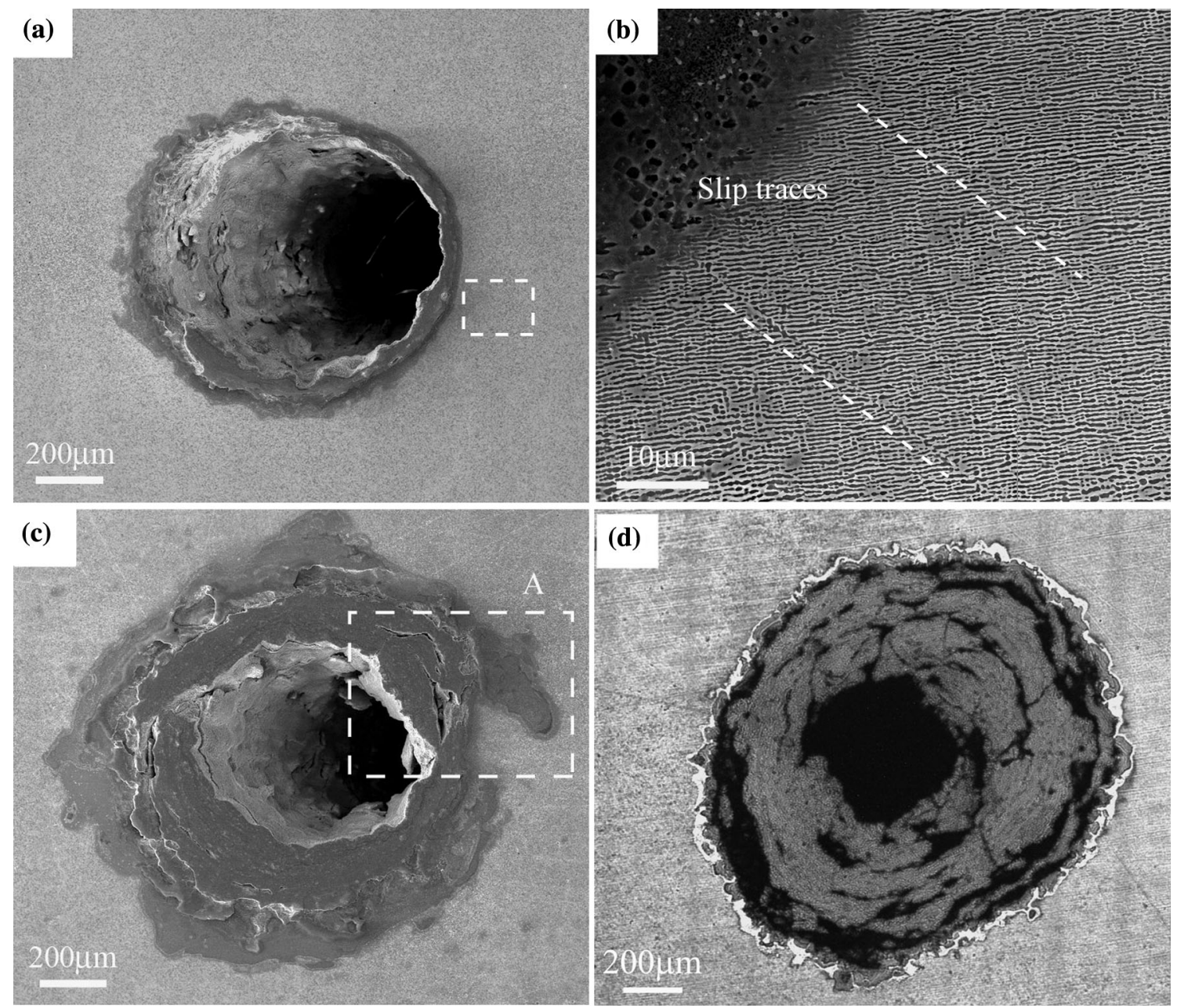

Fig. 7 Microstructural evolution around $60^{\circ}$ holes during TF tests: a 100 cycle, b zoomed view of rectangular area in a, c 180 cycles, d 540 cycles

given alloy with the same directional solidification parameters [22, 23]. When $K$ reaches a threshold value $K_{\text {th }}$, namely that the local tensile stress $\Delta \sigma$ simultaneously reaches the corresponding peak, the crack will initiate. Meanwhile, an oxidation layer forms at the edge of the hole, which cannot be elongated homogenously with the bulk material. Due to the disharmony between the oxidation layer and bulk material during deforming, microcrack is likely to initiate at such oxidized sites. It is cycling with this local tensile stress and fracture of oxidation layer that drives the TF crack to initiate at the acute side of the $30^{\circ}$ hole and then propagate. As for the Ni-based single crystal superalloy, the cracks propagate along the preferred orientation $<110>$ with the largest resolved shear stress. Moreover, the thermal stress or localized plastic deformation will enhance the diffusion process in the vicinity of the crack tip, which will accelerate the oxidation process. Meanwhile, the depletion of the $\gamma^{\prime}$-forming elements severely reduces the amount of $\gamma^{\prime}$; thus, the strengthening effect of $\gamma^{\prime}$ will be impaired in the $\gamma^{\prime}$-denuded zone. Hence, cracks are easier to propagate in this area.

With increasing skew angles, more deformation constraint is available at the acute side of the holes, and less strain concentration is expected. As for the $60^{\circ}$ hole, the stress concentrated at the acute side is not sufficient to cause crack initiation. During thermal cycles, the intensive slip traces at the edge of the hole help to release parts of the thermal stress. In addition, when rafting of $\gamma^{\prime}$ occurs, dislocation cluster is pinned at the lamellar $\gamma / \gamma^{\prime}$ interface, which blocks the movement of $\gamma / \gamma^{\prime}$ interface and retards the crack initiation [24, 25]. All these make no cracks initiate at the edge of the hole even after 580 cycles, and the same results were obtained for samples with $90^{\circ}$ hole.

It may be worthwhile to note that the number of cycles to produce cracks in the specimen with a skew hole was mainly governed by the local effects in the vicinity of the acute side, which may have serious design implications [19]. 

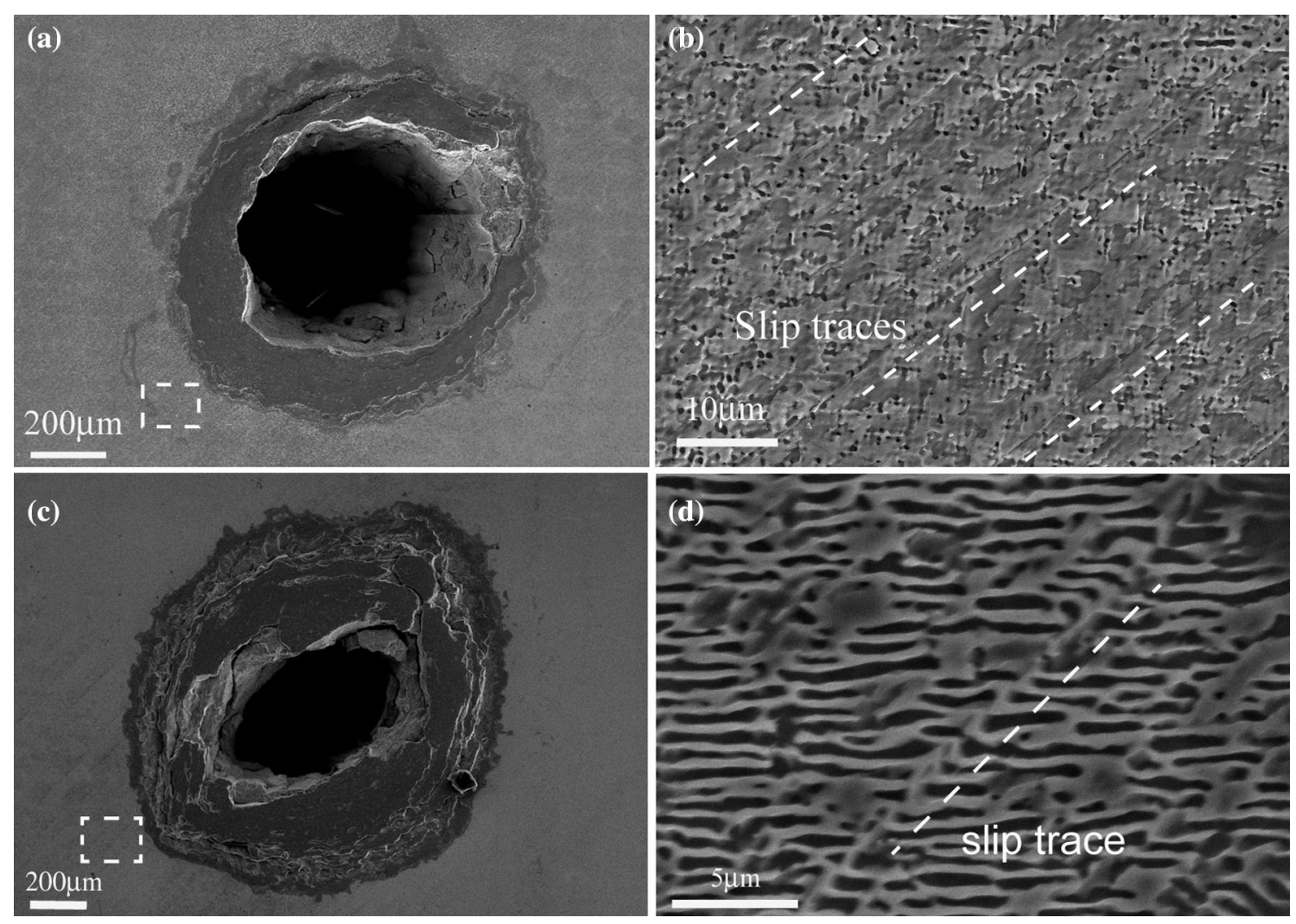

Fig. 8 Changes in $90^{\circ}$ holes after TF: a 140 cycles, b zoomed view of rectangular area in a, c 540 cycles, $\mathbf{d}$ zoomed view of rectangular area in c

\section{Conclusions}

1. The skew angles of the holes caused the stress concentration at the edge of the holes, especially at the acute side of the hole, which had a significant effect on the thermal fatigue behaviors of plate specimens with holes.

2. Due to less deformation constraint, the maximum stress concentration and the resultant equivalent tensile stress were developed at the acute side of $30^{\circ}$ hole. The local equivalent tensile stress combined with the disharmonic deformation between the oxidation layer and bulk material made the thermal fatigue crack initiate after 220 cycles and propagate along [0 $\overline{1} 1]$ direction for the specimen with the $30^{\circ}$ hole. However, as for $60^{\circ}$ or $90^{\circ}$ holes, more deformation constraint resulted in less strain concentration at the acute side. This would partly release thermal stress induced by intensive slip traces and the blocked movement of dislocation cluster at the lamellar $\gamma / \gamma^{\prime}$ interface due to $\gamma^{\prime}$ rafting all retarded the crack initiation even after 580 thermal cycles.

Acknowledgements This work was supported by the National Natural Science Foundation of China (No. 51201164) and the National
High Technology Research and Development Program of China (No. 2012AA03A511).

\section{References}

[1] A.E. Gemma, J.S. Phillips, Eng. Fract. Mech. 9, 25 (1977)

[2] F. Sun, J.Y. Tong, Q. Feng, J.X. Zhang, J. Alloys Compd. 618, 728 (2015)

[3] F.M. Olbersleben, N. Kasik, B. Ilschner, F. Rézaï-Aria, Metall. Mater. Trans. A 30, 981 (1999)

[4] V.S. Bhattachar, Int. J. Fatigue 17, 407 (1995)

[5] P.A. Sabnis, M. Maziere, S. Forest, N.K. Arakere, F. Ebrahimi, Int. J. Plast 28, 102 (2012)

[6] C.L. Dong, X.G. Yang, D.Q. Shi, H.C. Yu, Mater. Des. 55, 966 (2014)

[7] J.W.H. Price, B. Kerezsi, M. Chang, Eng. Fail. Anal. 11, 267 (2004)

[8] E. Glenny, T.A. Taylor, J. Inst. Metal. 88, 449 (1959)

[9] D.A. Woodford, D.F. Mowbray, Mater. Sci. Eng. A 16, 5 (1974)

[10] P.C. Xia, J.J. Yu, X.F. Sun, H.R. Guan, Z.Q. Hu, Rare Metal Mater. Eng. 37, 50 (2008)

[11] Y. Liu, J.J. Yu, Y. Xu, X.F. Sun, Rare Metal Mater. Eng. 38, 59 (2009)

[12] L. Wang, Z.J. Zhou, W.G. Jiang, D. Wang, J. Shen, L.H. Lou, Chin. J. Mater. Res. 28, 663 (2014)

[13] L. Wang, Z.J. Zhou, S.H. Zhang, X.D. Jiang, L.H. Lou, J. Zhang, Acta Metall. Sin. 51, 1273 (2015). (in Chinese)

[14] B. Baufeld, E. Tzimas, H. Müllejans, S. Peteves, J. Bressers, W. Stamm, Mater. Sci. Eng. A 315, 231 (2001)

[15] Z.X. Jin, J. Iron. Steel Res. Int. 5, 205 (1985) 
[16] Y. Zhou, S.X. Rao, Z. Zhang, Z.H. Zhao, Mater. Des. 49, 25 (2013)

[17] X.M. Wang, Y. Zhou, Z.H. Zhao, Z. Zhang, Acta Metall. Sin. (Engl. Lett.) 28, 628 (2015)

[18] S. Nagpal, N. Jain, S. Sanyal, Eng. J. 16, 1 (2012)

[19] F. Ellyin, Exp. Mech. 13, 305 (1973)

[20] Z.J. Zhou, L. Wang, J.L. Wen, L.H. Lou, J. Zhang, J. Alloys Compd. 628, 158 (2015)

[21] E. Sun, T. Heffernan, R. Helmink, Superalloys 2012, 351 (2012)
[22] C.L. Brundidge, D. Vandrasek, B. Wang, T.M. Pollock, Metall. Mater. Trans. A 43, 965 (2012)

[23] Z.D. Fan, D. Wang, L.H. Lou, Acta Metall. Sin. (Engl. Lett.) 28, 152 (2015)

[24] T. Ichitsubo, D. Koumoto, M. Hirao, K. Tanaka, M. Osawa, T. Yokokawa, H. Harada, Acta Mater. 51, 4033 (2003)

[25] N. Matan, D.C. Cox, C.M.F. Rae, R.C. Reed, Acta Mater. 47, 2031 (1999) 